\title{
Optimal Environmental Conditions and Nutrient Concentrations for the Synthesis of Bacterial Luciferase in Photobacterium phosphoreum
}

\author{
By M. H. ELEY* \\ Biochemistry Department, University of Georgia, Athens, Georgia, 30601, U.S.A.
}

(Accepted for publication 30 May 1972)

Several studies (Eley \& Cormier, I968; Cormier, Eley, Abe \& Nakano, I969; Eley et al. 1970) on intact organisms and partially purified luciferase preparations of Photobacterium phosphoreum (Bergey's Manual of Determinative Bacteriology, 1957) indicated that further studies on the purified luciferase from this bacterium might provide some new understanding about bacterial bioluminescence in general. These studies, which would require large quantities of luciferase, were begun with the search for a suitable medium for the large-scale production of the bacteria with high yields of luciferase. Of the several conditions found to enhance the synthesis of luciferase, yeast extract, aeration, $\mathrm{pH}$ and temperature produced the most dramatic effects. A medium has been formulated which, under optimal environmental conditions for this bacterium, promotes the synthesis of luciferase in high yield relative to the total soluble protein. Data in this paper also show that the bioluminescence rate in vivo is directly related to the luciferase activity in extracts.

\section{METHODS}

The strain of Photobacterium phosphoreum was obtained from Dr W. Terpstra (State University, Utrecht) and maintained on sterile slants of Difco Photobacterium Agar. At 2-week intervals the culture was streaked on sterile plates of the above medium and the brightest colonies (as judged by visual examination in a dark room) were transferred to slants in screw-cap test tubes. The slants and plates were incubated aerobically at $15{ }^{\circ} \mathrm{C}$. After good growth and luminescence were attained on the slants, the caps were sealed airtight and the tubes stored at $4{ }^{\circ} \mathrm{C}$.

For liquid culture of Photobacterium phosphoreum the media described in the Results and Discussion were modified from the standard medium containing the following per litre of deionized water: yeast extract (Fisher Scientific), $5 \mathrm{~g}$; tryptone (Fisher Scientific), $5 \mathrm{~g}$; $\mathrm{NaCl}, 30 \mathrm{~g} ; \mathrm{Na}_{2} \mathrm{HPO}_{4}, 5 \mathrm{~g} ; \mathrm{KH}_{2} \mathrm{PO}_{4}$, I g; glycerol, $3 \mathrm{ml}$. The liquid cultures were grown in Erlenmeyer flasks with cotton plugs with the volume of sterile medium $\mathrm{I} / 5$ the volume of the flask. The cultures were incubated at $\mathrm{I} 5{ }^{\circ} \mathrm{C}$, unless specified otherwise, with vigorous shaking.

Bacteria, for counting and light measurements in vivo, were measured either without dilution or after dilution into $30 \mathrm{~g} \mathrm{NaCl} / 1$. Bacteria for extraction of luciferase were harvested by centrifuging in an RC-2B Sorvall centrifuge with a GSA rotor at $10000 \mathrm{rev} / \mathrm{min}$ for $15 \mathrm{~min}$. For the light measurements in vitro the organisms were lysed in deionized water and the debris removed by centrifuging as described above.

Light emission by intact organisms and extracts was measured as previously described

* Present address: The Clayton Foundation Biochemical Institute, Chemistry Department, University of Texas at Austin, Austin, Texas, 78712 , U.S.A. 


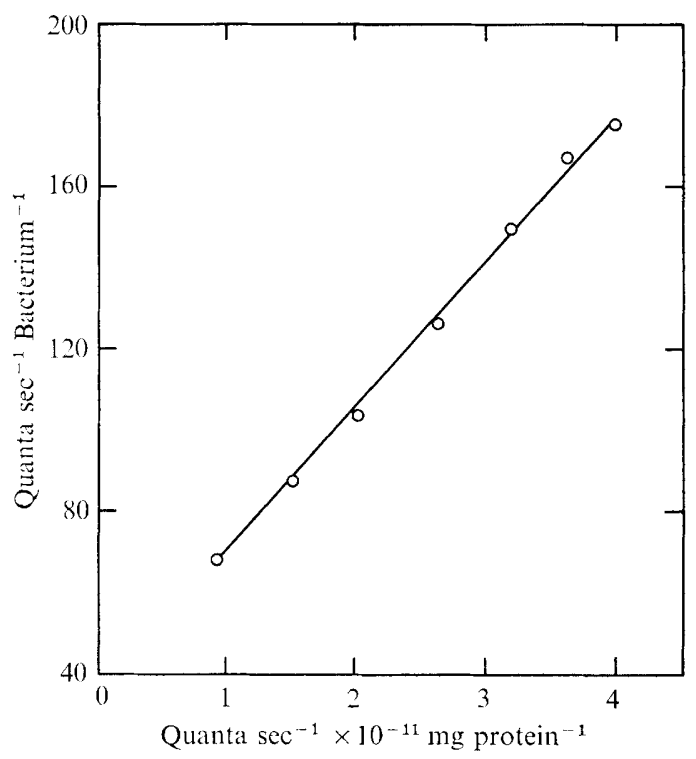

Fig. I. Relationship bstween bioluminescence in vivo and in vitro. The bacteria were harvested at $5 \mathrm{~h}$ intervals from a culture grown in the standard medium under optimum conditions for luminescence rate per bacterium as described in the text.

(Eley \& Cormier, 1968). The instrument readings were calibrated by the use of the luminol chemiluminescence standard (Lee, Wesley, Ferguson \& Seliger, 1966). Bioluminescence is expressed as quanta $/ \mathrm{s} / \mathrm{ml}$ of culture and luciferase specific activity expressed as quanta/s/mg protein. Protein concentration was estimated by a modified Biuret (Eley, I968). Bacterial numbers were determined by direct counting with a Vickers microscope and a Petroff-Hauser bacterial counting cell.

\section{RESULTS AND DISCUSSION}

Although Difco Photobacterium Agar supported growth and luminescence, Difco Protobacterium Broth was unsatisfactory for growing large-scale liquid cultures because of the $\mathrm{CaCO}_{3}$ precipitate which was difficult to separate from the harvested bacteria. A special medium was therefore needed since only sparse growth or weak luminescence was obtained with media previously reported for the liquid culture of this and other species (Harvey, 1952; Terpstra, 1958; Kuwabara et al. 1965; Hastings, Riley \& Massa, 1965). Yeast extract, tryptone, nutrient broth (Difco), and peptone (Difco) were tried alone and in combinations to supplement the standard medium with the yeast extract and tryptone omitted. It was found that a combination of yeast extract and tryptone $(5 \mathrm{~g}$ each/1) induced a more rapid increase in the luminescence rate per bacterium and a higher maximum luminescence rate per bacterium than the other media tried.

Salt is known to be a necessary component of the media of marine luminous bacteria. In the present study $30 \mathrm{~g} \mathrm{NaCl} / 1$ produced the highest luminescence rate per bacterium.

Maximum luminescence is obtained when this bacterium is grown in medium containing glycerol as carbon source (Hill \& Shoup, 1929). Several concentrations of glycerol from I to $5 \mathrm{ml} / 1$ were compared. A $3 \mathrm{ml}$ sample of glycerol/l of medium produced a somewhat higher luminescence rate per bacterium than other concentrations tried.

Growth at both $\mathrm{pH} 6.0$ and 6.5 gave maximum luminescence rates per bacterium. The 
growth rate and yield was about $50 \%$ higher at $\mathrm{pH} 6.5$ than at $\mathrm{pH} 6.0$. Therefore, the bacterium was cultured in the standard medium at $\mathrm{pH} 6.5$. A similar $\mathrm{pH}$ optimum was found earlier for maximum luminescence of suspensions of this bacterium (Johnson, 1947).

The effects of temperature on growth and luminescence of luminous bacteria have been found to vary with the species or strain (Harvey, I952). Incubation at $\mathrm{I} 5{ }^{\circ} \mathrm{C}$ was found to be optimal for this strain of Photobacterium phosphoreum when grown in the standard medium.

Bacterial bioluminescence is absolutely dependent upon oxygen. Vigorous shaking of cultures grown in flasks as described in Methods was adequate to produce maximum luminescence rate per bacterium without additional aerating apparatus.

For the maximum synthesis of bacterial luciferase in Photobacterium phosphoreum during growth in the standard medium, the $\mathrm{pH}$ should be adjusted to 6.5 and the culture incubated at $15{ }^{\circ} \mathrm{C}$ with vigorous shaking.

The gathering of data on luciferase synthesis during growth is based on the fact that the luminescence rate per bacterium is directly related to the luciferase content. Fig. I shows this direct relationship between the luciferase activities in vivo and in vitro. This fact allows one easily to determine the luciferase levels per bacterium at any time during the growth cycle. These studies have provided useful knowledge for the production of large quantities of Photobacterium phosphoreum with a high content of luciferase per bacterium.

This work was supported by grants from the U.S. National Science Foundation (GB28559XI) and the U.S. Atomic Energy Commission [AT(38-I)635]. The author was a U.S. National Science Foundation Graduate Trainee.

I thank Dr M. J. Cormier for his suggestions and for the use of his laboratory and equipment, and Mr D. Gorgas for his assistance in these experiments.

\section{REFERENCE}

Bergey's Manual of Determinative Bacteriology, 7 th edn, pp. 193--195 (I957). Edited by R. S. Breed, E. G. D. Murray \& N. R. Smith. Baltimore: Williams and Wilkins.

Cormier, M. J., Eley, M., Abe, S. \& Nakano, Y. (I969). On the requirement and mode of action of longchain aldehyde during bacterial bioluminescence. Photochemistry and Photobiology 9, 35I-358.

Eley, M. H. (1968). Studies on the bioluminescence of Photobacterium phosphoreum: some properties of the in vivo and in vitro luminescence and a partial purification of the luciferase, pp. I-II8. M.S. Thesis, University of Georgia, Athens.

ElEy, M. \& CORMIER, M. J. (I968). On the function of aldehyde in bacterial bioluminescence: evidence for an aldehyde requirement during luminescence from the frozen state. Biochemical and Biophysical Research Communications 32, 454-460.

Eley, M., Lee, J., Lhoste, J.-M., Lee, C. Y., Cormier, M. J. \& Hemmerich, P. (I970). Bacterial bioluminescence: comparisons of bioluminescence emission spectra, the fluorescence of luciferase reaction mixtures, and the fluorescence of flavin cations. Biochemistry 9, 2902-2908.

Harvey, E. N. (1952). Bioluminescence, pp. I-95. New York: Academic Press.

Hastings, J. W., Riley, W. H. \& Massa, J. (1965). The purification, properties, and chemiluminescent quantum yield of bacterial luciferase. Journal of Biological Chemistry 240, I473-148I.

Hill, S. E. \& Shoup, C. S. (1929). Observations on luminous bacteria. Journal of Bacteriology $\mathbf{x} 8,95-99$.

Johnson, F. H. (1947). Bacterial bioluminescence. Advances in Enzymology 7, 21 5-264.

Kuwabara, S., Cormier, M. J., Dure, L. S., Kreiss, P. \& Pfuderer, P. (1965). Crystalline bacterial luciferase from Photobacterium fischeri. Proceedings of the National Academy of Science of the United States of America 53, 822-828.

Lee, J., Wesley, A. S., Ferguson, J. G. \& Seliger, H. H. (1966). The use of luminol as a standard of photo emission. In Bioluminescence in Progress, pp. 35-43. Edited by F. H. Johnson \& Y. Haneda. Princeton: Princeton University Press.

TERPS TRA, W. (1958). The interaction of luciferase, flavin mononucleotide and long-chain aldehydes in the light reaction catalyzed by preparations of luminous bacteria. Biochemica et biophysica acta 28, I 59-168 